\title{
Relationship between Gender and Stress among the Staff Members of Educational Institutions
}

\author{
Preeti Yadav, Samra Sultana
}

\begin{abstract}
Stress is a topical subject. It has assumed great significance in the present day world. Today, modern man is afflicted with stresses of various kinds. The origin of these stresses may be found in several types of frustrations, conflicts or pressures of the modern day life pattern. As the stress may emanate from either of these roots, personal experiences of stress differ. Role is the expectation of works from a person in respect of the social system and his own expectations. For better results the role has to be evaluated, shared with others and if these role expectations conflict with each other, it creates stress in role's position. Researchers working on the increasing complexity of organizations have recognized the potential of conflict and stress in the performance of organizational roles. This paper is an effort by the researcher to know about the link relationship of gender and level of stress in staff members of educational institutions.
\end{abstract}

Keywords: Stress, Gender, Role Stress, Educational Institutions, etc.

\section{INTRODUCTION}

Stress is originated from the word 'Stringere' of Latin (edworthy, 2000). Stress is the basic part of life and refers to the hardships, strain, and adversity and arises out of the adverse situation as of physical, psychological and emotional unbalance of demands and supply. In seventeenth century it was referred to hardship and strain. In the eighteenth century stress denoted force, pressure, strain and long efforts. For the first time this was used by Selye in the year 1936 who referred it as response of the body which is not specific. Later this term was more detailed and Lazarus \& Cohen (1980) described it as a response from a person to any phenomenon. It was clear that individuals do not react directly to any situation but to the environment. These situations might create trouble and it dependent on person to person, the demands and resources. The term relates to the lack of fit between an individual and the sorroundings. (Harrison 1978).

Role stress can be described as the stress experienced by the person as of their Job in the organization. It is caused because of various types of roles and responsibilities a person has to perform at their workplace and it causes because of the deviation in performing these roles and responsibilities. Most of the times it's the role and the responsibility which creates stress and these roles are called the role stressors.

Revised Manuscript Received on November 11, 2019.

* Correspondence Author

Dr. Preeti Yadav, Associate Professor, Amity Business School, Amity University, Jaipur.

Samra Sultana, Research Scholar, Amity Business School, Amity University, Jaipur. 


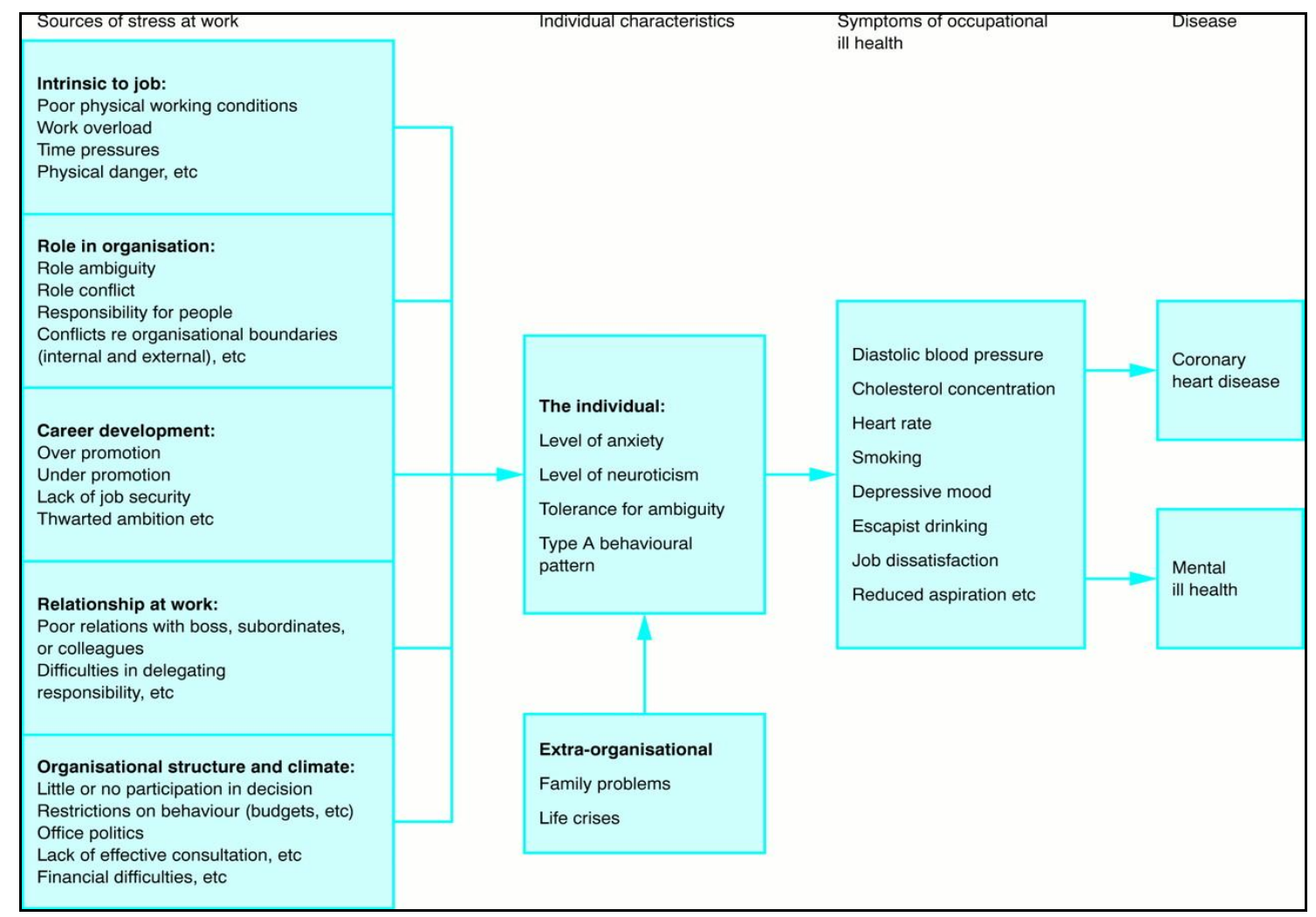

Source-adopted from the Cooper CL, Marshall J. (published in Occupational sources of stress: a review of the literature relating to coronary heart disease and mental ill health. J Occupy Health Psychol1976; 49:11-28

\section{REVIEW OF LITERATURE}

The word stress is defined by various scholars and authors.; G. Chrousos; Sapolsky, 2004; Oxington, 2005) Sapolsky (2004) defined stress as the "A stressor is anything in the outside world that knocks you out of homeostatic balance and the stress response is what your body does to reestablish homeostasis"

G. Chrousos defines the stress as "the threat or perceived threat condition of homeostasis, which is established through a complex web of behavioral and physiological responses of the body to adapt" (Chrousos, 2009).Lazarus R.S and Folkman S. said the stress as "the result of interaction between the individual and the environment. When persons feel that they cannot cope with the number of abilities and skills in environmental requirements, is experiencing stress" (Berjot\&Gillet, 2011). (Awe, et al. 2016). The occupational stress which poses a formidable challenge leaves both physical as well as emotional implications on the individual (Dupéré et al., 2015).

Siddiq, (2016) in his paper found that environment at workplace is related to the degree of stress. The authors put forward that demands of different jobs potentially puts a pressure on the employees in the organization. Trouble at workplace can be due to many reasons like Stress at bad work culture, shifts of workers, extra work, working time , role conflicts and its ambiguity and so on.

Latif, et al. (2016) showed that stress on the organization may result in muscular tension, heart disease, high or low blood pressure which may leads to 'gastro and intestinal problems , respiration problems, muscle and skeletal troubles, skin infections, immunity issues and problems related to psychological state. Though these particular mechanism which become the medium of chronic or severe stress or may result in ill health is still unclear but it has been seen that these above said fictional changes in the body may result in hormonal misbalance and subsequently but it was found that functional changes in increase hormonal systems can lead to high chances of illness. (Syed, et al. 2015). According to Gardazi, et al. (2016), they studied and found that stress creates threats to people if the psychological and physiological elements are pushed beyond their stable limits. With these entire reference and studies researcher found there is a gap to study about status of gender and level of stress in staff of educational institutions. Researcher has designed the given objective and hypothesis:

Objective:

To study about various stress causes and level of stress in relation to gender in various educational institutions of Rajasthan State.

Hypothesis:

The gender has not significantly equal effect of stress in educational institutions of Rajasthan State.

\section{RESEARCH METHODOLOGY}

The researcher has used The Pareek's Organizational role stress (ORS) scale for the current as research. Organizational role stress (ORS) scale because it a classic inventory for knowing the of stress related to role in an association. So, it was believed to be relevant for the current piece of work. (Bhattacharya \& Basu). 
The researcher has collected data from 500 teachers of Rajasthan state from private and government school. The sample was taken randomly and conveniently.

For analysis of data researcher has used mean distribution values of various stress variables as per gender.

\section{ANALYSIS \& FINDINGS}

The table given below summarizes the respondents' characteristic with regard to their age, gender, income, religion. The participants in the study consist of total 500 respondents, 139 male and the 361 female.

Table 1 - MALE AND FEMALE RESPONDENTS

\begin{tabular}{|c|c|c|c|}
\hline GENDER & FREQUENCY & $\begin{array}{c}\text { PERCEN } \\
\mathrm{T}\end{array}$ & $\begin{array}{c}\text { CUMULATIVE } \\
\text { PERCENT }\end{array}$ \\
\hline MALE & 139 & 27.8 & 27.8 \\
\hline FEMALE & 361 & 72.2 & 100 \\
\hline TOTAL & 500 & 100 & \\
\hline
\end{tabular}

\section{Graph 1 - Gender of the Respondents}

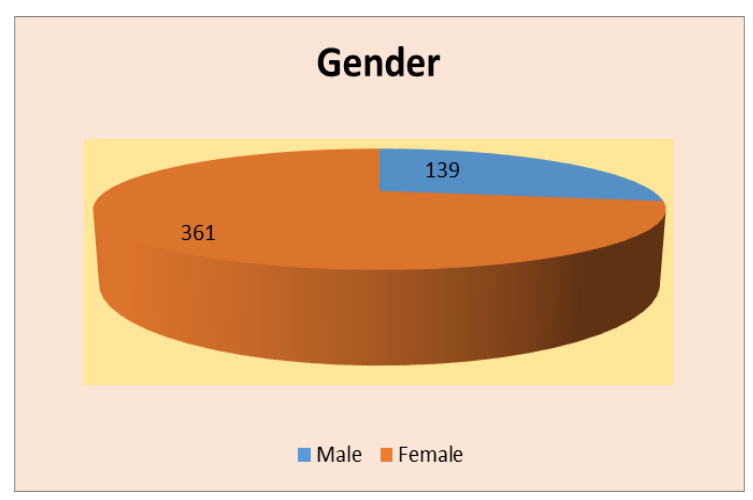

According to the data given in the table above, the sample consists of the $72.2 \%$ of the female and $27.8 \%$ of the male

respondents. Major difference between both the genders was found. This may be because teaching as a profession is most preferred by women and only a low percentage of men are attracted towards this profession. According to national statics around $48 \%$ of the total faculty members were female in 2015-16 in comparison to $47.70 \%$ in 2014-2015. The female staff was just $40.33 \%$ in $2005-2006$. This shows that the number of female staff was steadily increasing. The report also shows that 'urban areas had higher ratio of female staff at almost $66 \%$ in comparison to village region with $41 \%$. Irrespective of the type of institutions, a significant difference is noticed in the case of female faculty members in educational institutions under private (56 percent) and government managements (42 percent).'

The effect of role stress across the gender can be seen in the table given below:

Table 2- Analysis across the Gender

\begin{tabular}{|l|l|l|l|l|l|l|}
\hline \multirow{2}{*}{$\begin{array}{l}\text { GENDE } \\
\mathrm{R}\end{array}$} & \multicolumn{2}{|l|}{$\mathrm{F}$} & \multicolumn{2}{l|}{$\mathrm{M}$} & \multicolumn{2}{l|}{ Total mean } \\
\cline { 2 - 7 } & Mean & $\begin{array}{l}\text { Standard } \\
\text { Deviation }\end{array}$ & $\begin{array}{l}\text { Mea } \\
\mathrm{n}\end{array}$ & $\begin{array}{l}\text { Standard } \\
\text { Deviation }\end{array}$ & $\begin{array}{l}\text { Mea } \\
\mathrm{n}\end{array}$ & $\begin{array}{l}\text { Stan } \\
\text { dard } \\
\text { Devi } \\
\text { ation }\end{array}$ \\
\hline IRD & 1.93 & 0.71 & 1.92 & 0.63 & 1.92 & 0.69 \\
\hline RS & 2.02 & 0.61 & 2.02 & 0.68 & 2.02 & 0.63 \\
\hline REC & 2.36 & 0.89 & 2.14 & 0.69 & 2.14 & 0.84 \\
\hline RE & 2.38 & 0.47 & 2.42 & 0.39 & 2.43 & 0.45 \\
\hline RO & 2.72 & 0.62 & 2.71 & 0.64 & 2.71 & 0.63 \\
\hline RI & 1.91 & 0.64 & 1.77 & 0.63 & 1.77 & 0.64 \\
\hline PI & 1.84 & 0.47 & 1.84 & 0.46 & 1.85 & 0.47 \\
\hline SRD & 2.28 & 0.57 & 2.17 & 0.65 & 2.25 & 0.60 \\
\hline RA & 2.28 & 0.84 & 2.11 & 0.70 & 2.23 & 0.81 \\
\hline Rin & 2.47 & 0.5 & 2.43 & 0.50 & 2.43 & 0.50 \\
\hline
\end{tabular}

Graph 2- Analysis across the Gender

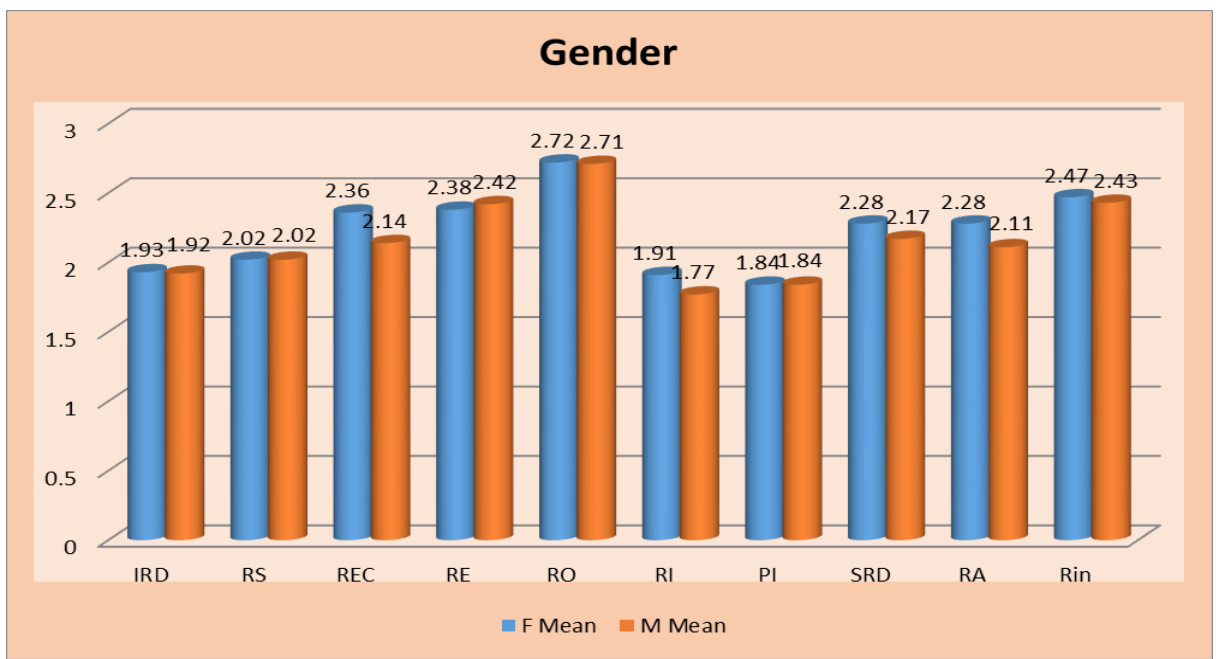

The outcome of the analysis shows that female faculty members are found to be under more stress in comparison to their male counterparts.
Comparative analysis across the gender indicates that the 
female faculty feels more stress in compare to the male faculty.

Hema Sharma (2017), in her research, argued that female faculty members are making more use of emotion focused coping strategies to deal with stress than male faculty members. Female faculty members have been found to make more use of mental disengagement, venting, behavioral disengagement, emotional social support and acceptance. Further, it is evident from Table 5.6 that females are also reporting more stress in this case. This stress may be due to parents of students, students themselves, institutes' administration and their colleagues as compared to their male counterparts who are relying more on problem focused coping. Across individual's stressors, significant difference have been observed among this group of faculties. The analysis revealed that both male and female feel stressed with Role Overload, here the mean value for the female faculty (2.72) is higher than the male faculty. (2.71).

Role Inadequacy is the second major factor which is seen as more stress inducing by both male and female faculty. The male faculty members feel more role erosion stress in comparison to the female faculties.

Role Expectation Conflict was also found as the major stressors between both the male and female faculty. The female faculties were found having more role stress ( $m-2.36)$ in comparison to the male faculties (2.14).

Role Inadequacy was very high among both the genders. The female faculty members feel more inadequacy in their assignment or the task they have to perform as the teachers. While interviewing them it was found the female faculty members found it more inadequate to do tasks assigned to them other than teaching

Significant differences were also found in Role Ambiguity. The female faculty members found the lack of clear guidance in terms of the other assignments given to them from time to time other than the teaching one stressful.

The stress on the Personal Inadequacy has been seen the lowest in both male and female faculty members as they found themselves competent enough for the role they have to perform.

The results obtained through the present research are in concordance with the results of Bushra Bano's (2013) research on the police personnel where she observed that female employees feel more stress in comparison to male employees.

ASSOCHAM Social Development Foundation in its 2012 report on, "Current Conditions and Development Trends Amongst Female Office Workers" points out that about 40\% among the women find that the job which they do demand too much while the pay is lesser as compared to the work done by them.

So the discussion above reveals that there lies a difference between the faculty members with regards to gender. Female faculty members feel more stress in comparison to male faculty members. Finally researcher has failed to accept the hypothesis.

\section{REFERENCES}

1. Bhattacharya, S., \& Basu, J. (2007). Distress, wellness and organizational role stress among IT professionals: Role of life events and coping resources. Journal of the Indian Academy of Applied Psychology, 33(2), 169-178.

2. Cooper, C. L., \& Marshall, J. (1978). Understanding executive stress (1-9). London: Macmillan Press.

3. Gordon, J. (2004). Pfeiffer classic inventories, questionnaires, and surveys for training and development. San Francisco, CA: John Wiley \& Sons.

4. Hussain, S., Malik, M. I., Hyder, S., Khan, M. A., \& Anwar, N. (2016). Discrimination and career mobility among female bank employees. Pakistan Business Review, 18(2), 468-

5. Harrison, R. V. (1978). Person-environment fit and job stress. In C. L. Cooper \& R. Pyne (Eds.). Stress at work (175-205). New York: John Wiley \& Sons.

6. Hinkle, L. E. (1973). The concept of stress in the biological and social sciences. Science, Medicine and Man, 1(1), 31-48.

7. Pareek, U. (1982). Organizational role stress scales (manual, scale, answer sheet). Ahmedabad: Navin Publications.

8. Pareek, U. (1993). Making organizational roles effective. New Delhi: Tata McGraw-Hill Publishing.

9. Pestonjee, D. M. (1999). Stress and coping - The Indian experience (2nd ed.). New Delhi: Sage Publications. 